\title{
Launching and steering flagship Lepidoptera for conservation benefit
}

\section{Tim R. New}

Department of Zoology, La Trobe University, Victoria 3086, Australia

Email: t.new@latrobe.edu.au

Date of publication (online): 26 June 2011 Date of publication (print): 26 June 2011 ISSN 0974-7907 (online) | 0974-7893 (print)

Editor: Robert Michael Pyle

\section{Manuscript details:}

Ms \# 02621

Received 02 November 2010

Final revised received 04 April 2011

Finally accepted 09 May 2011

Citation: New, T.R. (2011). Launching and steering flagship Lepidoptera for conservation benefit. Journal of Threatened Taxa 3(6): 18051817

Copyright: (c) Tim R. New 2011. Creative Commons Attribution 3.0 Unported License. JoTT allows unrestricted use of this article in any medium for non-profit purposes, reproduction and distribution by providing adequate credit to the authors and the source of publication.

Author details: Emeritus Professor Tim New has worked on many aspects of insect conservation policy and practice, and has published extensively on these themes.

Acknowledgments: This essay is based on a keynote talk prepared for the Third Asian Lepidoptera Conservation Symposium, Coimbatore, India, in October 2010. I wish to thank the primary organisers, Dr. B.A. Daniel and Dr. C. Gunasekaran, for inviting me to this meeting. I am very grateful to Dr. Paul Waring for delivering this talk in my unavoidable but unexpected absence, and to two reviewers for their helpful comments.

\begin{abstract}
Lepidoptera, particularly butterflies and large moths, are popular targets for conservation efforts and as flagship species can help to publicize the need for habitat and resource protection and the ecological value of invertebrates. Here I present an overview of the relevant issues in selecting and promoting flagship species, and discuss how local community support for conservation may be encouraged, using examples from Australia.
\end{abstract}

Keywords: Australia, butterflies, conservation education, icon species, moths, species conservation.

\section{PROBLEMS OF COMMUNICATION IN INSECT CONSERVATION}

Perceptions of insects vary widely, but one predominant attitude is that they are generally pests that should be suppressed or eradicated rather than conserved - an image that is incompatible with efforts to conserve insects. This 'perception barrier' has many components, and is confounded by the high numbers of species involved - a factor that can easily induce feelings of overwhelming helplessness at the magnitude of conservation need. It is sobering to reflect that entomologists cannot yet agree within orders of magnitude how many kinds of insect exist on earth. Indeed counting species has become somewhat of an industry in itself, even though it is not practical conservation, simply an indication of the magnitude of the tasks we face as natural environments are diminished and changed progressively by human activities. It is pertinent to contrast conservation acceptance for insects with that accorded to vertebrates, which are much less diverse but more tangible and appealing to many people. Whereas in ethical terms, a rare beetle or fly may be just as needy of attention as a tiger or elephant, they tend to be diminished in perception. However, it is perhaps salutary that, despite the massive conservation resources they have received and continue to receive, almost half the world's 634 primate species are still severely threatened from loss of habitat and exploitation for bush meat and trade (IUCN 2010). Even strongly resourced and globally-supported

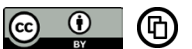

OPEN ACCESS | FREE DOWNLOAD
This article is part of the peer-reviewed Proceedings of the $3^{\text {rd }}$ Asian Lepidoptera Conservation Symposium (3ALCS-2010) jointly organized by the IUCN SSC South Asian Invertebrate Specialist Group (SAsISG); Department of Zoology, Bharathiar University; Zoo Outreach Organisation and Wildlife Information Liaison Development, held from 25 to 29 October 2010 at Coimbatore, Tamil Nadu, India. http://www.zooreach.org/3alcs2010.html 
vertebrate conservation programs directed at species of almost universal appeal do not assure their targets of any sustainable future. They show that the attitudes and needs of local communities and their support for conservation efforts are of critical importance to success.

Conservation of insects is about far more than individual species. It involves the heart of ecological sustainability and habitat conservation, with the roles of insects and other invertebrates, identifiable or not, as the major governors of processes in terrestrial and freshwater ecosystems. As E.O. Wilson famously pointed out some years ago, invertebrates are 'the little things which run the world' (Wilson 1987). Our role is to emphasize this point and explain it at every opportunity, and at the same time promote insect conservation through any means available to us. Because many people can relate to species as meaningful entities, and can see parallels between 'saving the orangutan' or the Black-headed Coucal and 'saving the Queen Alexandra's birdwing', individual species considerations are a valuable focus.

The practical dilemma is how to select the insect species that have greatest impacts on the ways we can make conservation effective and in how political capital may be garnered through demonstrating success and wider benefits. Some focus on those taxa that are better-known and more acceptable to the public is a logical way to select from amongst the hordes of insect species that may be threatened, or nominated as such under protective legislation. Triage is almost inevitable in any such context, but with the reality that selecting a species for attention may also increase risks to others, equally or even more deserving, by precluding them from equivalent attention. Any such selected species is in essence a flagship for wider conservation interest.

\section{WHAT IS AN ICON OR FLAGSHIP SPECIES?}

Flagship species are 'charismatic species that attract public support' (Andelman \& Fagan 2000). Many have other positive values that may render them valuable as surrogates, such as by becoming umbrella or indicator species in some way but, as Simberloff (1998) emphasized, this is not a prerequisite and a flagship must simply 'arouse public interest and sympathy' as a symbol of conservation concern. Despite its original religious connotation, the term 'charisma' as applied in conservation incorporates 'ability to influence or impress people', so that a flagship species is broadly a 'rallying point' (or marketing tool) for conservation concern. How it is perceived depends largely on the human context in which it occurs. Most commonly, 'flagship species' are large vertebrates, particularly mammals or birds - and the perceptions of large carnivores, for example, may differ markedly with proximity and chances of being eaten! International perceptions of 'charisma' may not always be emulated locally, so that the challenge of 'universal charisma' may be daunting. Even for one of the most favoured insect groups, dragonflies, perceptions may range from important cultural icons to pests of aquaculture operations through larval depredations on hatchling fish. In general, butterflies and some other Lepidoptera have overcome this acceptance hurdle, at least to the extent of their conservation not being actively opposed. However, understanding 'biophilia' is complex (Simaika \& Samways 2010); suffice, here, to note that some insects are indeed sympathetically considered because 'people like them'.

Knowledge of insects is uneven across different major taxonomic groups. Many groups are poorly documented, with knowledge unlikely to improve greatly. These insects include many of the most diverse taxa, such as the vast array of small parasitoid Hymenoptera and many families of small beetles and flies, as well as whole orders of insects that intrude little onto public awareness or concern, and remain of little concern other than to a small handful of specialists. Psocoptera are one such example amongst these 'meek inheritors' (New 2000), and are unlikely ever to become icons as wider conservation rallying points.

In contrast, some insect groups are accepted as wellknown and 'popular' - amongst these, butterflies are paramount, but followed by Odonata, some larger moths and some larger beetles, with this familiarity stemming largely from hobbyist interests, mainly collecting. As noted in the first of this series of symposia 'Big colourful butterflies invoke the 'vertebrate' approach to Lepidoptera conservation because they are .... charismatic species that imply 'heroic' conservation measures should be taken ....' (Kitching 2007). More generally 'Animal beauty is a paradigm of aesthetic value' (Hettinger 2010). Collectively, these 'popular' insects constitute a high proportion of the species on 
which conservation has been traditionally focused, because perception is positive and knowledge has become sufficient to detect declines and threats, by people likely to be concerned about these, and to publicize those concerns. Particularly in parts of the northern temperate region, 'butterfly conservation' has long been accepted as respectable and an integral part of wider conservation need, with that acceptance gradually inducing emulation elsewhere. One outcome is the acceptance we see today - the desire and sincere motivation to conserve Lepidoptera in parts of the world that are less sympathetic and less well-resourced but which harbour high proportions of the world's 20,000 or so butterfly species, and where it is important that the limited support available is used to the greatest possible effect. The premise advanced in the Hong Kong declaration (2007), namely 'that the Lepidoptera have a special place in human perception, culture and nature appreciation', underpins much of the attitude and approaches to using them for advocacy. In addition (a) many are themselves targets for individual species conservation and (b) many species or assemblages may be valuable 'tools' in being putative surrogates for wider conservation of the biotopes in which they occur, and of the coexisting but little-heralded accompanying 'biodiversity'. It is perhaps important to emphasise that, despite many advocacies for use of butterflies and, more rarely, of other Lepidoptera as indicators or surrogates, rather few studies have actually demonstrated this by statistical analyses confirming correlation with other taxa (see Fleishman \& Murphy 2009). However, single species conservation studies of insects have been almost wholly developed in well-resourced temperate regions, with relatively low species richness and many resident entomologists, and the logistic impediments to developing parallels elsewhere remain formidable. Moves for habitat protection have largely taken the place of this 'fine focus' insect conservation in the tropics, for example. Some of the reasons for this have been discussed recently for tropical butterflies (Bonebrake et al. 2010), with the need for more individual species studies emphasised.

Lepidoptera, our major focus here, have been referred to as 'Ambassadors of biodiversity', and are viewed also as umbrella taxa purported (but, as noted above, only rarely proven) to be surrogates for much wider conservation effort as either single species or diverse assemblages (New 1997). However, they fall unevenly into three major functional groups ('butterflies', 'macromoths', 'Microlepidoptera', as terms used widely amongst hobbyists, in particular) in conservation assessment - and the differences between these are evident even amongst the putatively well known western European fauna. These groups differ greatly in attributes suitable for use as flagships, and it is instructive to compare and contrast their relevant features, in order to suggest relativity of value in what a flagship species should and may achieve. Consider the following relative features for butterflies: (i) low species richness within a sound taxonomic framework so that many taxa are both recognisable and identifiable reliably; (ii) long history of collector interests based on aesthetic appeal and diurnal activity likely to have led to production of illustrated handbooks facilitating further interests; (iii) reasonable general framework of biological understanding and distributional information, often with valid comments on 'rarity' and susceptibility to environmental changes; (iv) these generalities augmented by detail from an increasing number of species conservation cases in many parts of the world and covering diverse taxa and biotopes as examples; and (v) high appeal and sympathy for their wellbeing, with rather little fear of actual or economic damage. These advantages are shared with some larger moths, mainly showy families such as Saturniidae (with economic benefits an additional advantage) and Sphingidae, or diurnal taxa that may be thought of as 'honorary butterflies' because they are visible, so equally amenable to study, and often colourful!

In contrast, many other macromoths are nocturnal and less accessible, and belong, with Microlepidoptera, firmly to the largely unknown (especially in the tropics) insects still viewed with considerable suspicion and for which knowledge is grossly inadequate to make any detailed case for species conservation need or, even, to define major centres of richness or endemism other than in very general terms. In noting that the number of described Microlepidoptera in south east Asia was around 6000 species, Robinson et al. (1994) commented also that the number still to be discovered was likely to be 'at least the same number again'. Two practical problems are associated with inability to gain flagship status: (i) that high numbers of unidentified or difficult to identify described species render many identifications of species within those faunas tentative 
or uncertain, and (ii) flagships are ideally conspicuous most moths, being crepuscular or nocturnal in activity, are not seen as easily unless they are deliberately sought. Many people are largely unaware of them. In contrast, the conspicuousness of diurnal butterflies renders them far more accessible, with the greater interest contributing to greater knowledge by a greater workforce. As Kendrick (2007) emphasised, far more people appreciate butterflies than appreciate moths, with one outcome being that reliable information on conservation status and needs is also markedly less for moths. Species accorded flagship status are a minute fraction of the total number of around 160,000 described Lepidoptera and an estimated 500,000 species that may exist (Kristensen et al. 2007), and the sheer diversity of these, and other insects, can easily induce feelings of bewilderment in seeking how conservation may best be pursued.

Only in parts of Europe is it currently possible to evaluate conservation status of many Microlepidoptera other than in the most generalised terms, reflecting attention from substantial numbers of resident enthusiasts. Kristensen et al. (2007) noted that the 'average amateur lepidopterist' ('having exhausted the challenges [at the collector's level!] presented by the local butterflies': Kristensen et al. 2007: 708) tends to make the transition from butterflies to macromoths and subsequently often to micromoths, of the national fauna, rather than to butterflies of neighbouring countries. Elsewhere, however, in any practical sense, Microlepidoptera are both unknown and unknowable as candidates for species-focused conservation; together with Psocoptera and many others, they can be conserved only by assuring that the ecosystems in which they occur are sustained (Franklin 1993).

Perhaps the essence of a flagship species is that it is 'visible', broadly seen as worthy of conservation, and accepted as such by the wider community rather than by scientist advocacy alone. It thus becomes a 'symbol' of local, regional or national interest - an ambassador for insect conservation together with the habitats on which it and they depend, and able to help in fostering both cooperation and participation in conservation activities. Local pride is often important, so that narrow range endemics may be particularly suitable for promotion. Some unusual biological feature or attribute, novelty value, may capture public interest and help considerably in the important steps of communication and education so vital in enlisting and sustaining community interests. Wider conservation importance for the species (for example, indicator or umbrella values - although the terms may lead to confusion in defining its role) may augment its functional importance considerably.

Fundamentally, a flagship (or icon) species is one that is readily recognised, ideally has some 'charisma', and can be used in its own right to publicise, encourage and sustain broader conservation endeavour for its own benefit and for that of the environment in which it can thrive.

\section{HOW CAN WE MAKE A SPECIES INTO A FLAGSHIP?}

Criteria that may be useful to consider in deciding whether a particular species might be a useful flagship are numerous, but may have a high emphasis on local significance and importance (Table 1).

For this adoption to occur, it follows that wide support for conservation must be canvassed, and seen as justified and important by demonstrated ('evidence-based') conservation need. Formal listing of a species may be useful, even necessary, to gain

Table 1. Ten criteria for consideration in choosing effective flagship species (after Bowen-Jones \& Entwistle 2002)

\begin{tabular}{|c|c|}
\hline Criterion & Comments \\
\hline Geographical distribution & $\begin{array}{l}\text { Within regional area of interest. } \\
\text { Endemic or restricted distribution may } \\
\text { increase local importance }\end{array}$ \\
\hline Conservation status & $\begin{array}{l}\text { Traditionally, high risk, but common } \\
\text { species may also be valuable }\end{array}$ \\
\hline Ecological role & $\begin{array}{l}\text { Benefit increased if has some critical } \\
\text { or central role in ecosystem: provides } \\
\text { opportunity to explain importance }\end{array}$ \\
\hline Recognition & $\begin{array}{l}\text { Ideally distinctive and not confused with } \\
\text { other species by target audience }\end{array}$ \\
\hline Existing usage & $\begin{array}{l}\text { If used elsewhere, may be useful } \\
\text { endorsement, but might also create } \\
\text { mixed messages; avoid conflicts of } \\
\text { interest }\end{array}$ \\
\hline Charisma & $\begin{array}{l}\text { Often subjective and variable. (Other } \\
\text { novelty or interest may be as important) }\end{array}$ \\
\hline Cultural significance & $\begin{array}{l}\text { Identify carefully. May provide } \\
\text { opportunities for endorsement }\end{array}$ \\
\hline Positive associations & $\begin{array}{l}\text { Increase likelihood of effectiveness } \\
\text { (Strong associations are not necessarily } \\
\text { positive) }\end{array}$ \\
\hline Traditional knowledge & $\begin{array}{l}\text { Valuable source of information. Provide } \\
\text { opportunities for reinforcement and } \\
\text { expansion }\end{array}$ \\
\hline Common names & $\begin{array}{l}\text { May influence public perception. May } \\
\text { need to change to improve popular } \\
\text { image }\end{array}$ \\
\hline
\end{tabular}


official recognition and may be a passport to accepted worth. Lists of threatened species can easily become very long and strongly biased towards particular taxonomic groups; Schedule 1 of the Indian Wildlife (Protection) Act 1972, for example, includes 128 butterfly taxa and the only other insect is a dragonfly. Such lists, with this Act listing 450 butterflies, many of them subspecies that are difficult to recognise, across the three relevant schedules, are invaluable in demonstrating the vast scales of conservation need to politicians and managers, but engender a feeling of helplessness in deciding how to proceed constructively. Fleets (species lists) need flagships for guidance and focus, and large fleets (long species lists) may need especially influential flagships with umbrella capacity. However, not all listed insect species become practical flagships. Some others become flagships almost by default, simply from the attention they receive and this is perhaps the most frequent context in which they are launched. They may be elevated retrospectively, to the benefit of all involved, as they become betterknown and achieve notoriety. This fortuitousness is rather different from deliberately commissioning flagship species from amongst a fleet of possible threatened and ecologically varied candidates, based on defining the desirable parameters and outcomes and, possibly, complementarity with other species efforts. Thus, in a common scenario, we may be faced with a decision to elevate 'more butterflies' (a strategy increasingly likely to be fruitful as the bulk experience on this group continues to be augmented and still more species contribute to the pool of experience and knowledge) or, by incorporating other insects to emphasise 'more variety', adopt a different strategy and convey a rather different political message. This necessitates a pragmatic decision to either capitalise on our greatest expertise and demonstrated capability (butterflies) or to take a greater risk for possibly wider ecological advantages. In Victoria (Australia), for example, the trio of flagship species comprising a butterfly (the Eltham Copper, Paralucia pyrodiscus lucida), a damselfly (the Ancient Greenling, Hemiphlebia mirabilis) and the Giant Gippsland Earthworm (Megascolides australis) convincingly demonstrated some aspects of the ecological variety and roles of threatened invertebrates at the time the State's conservation act was being developed in the late 1980s (Yen et al. 1990).
Choice amongst taxa for conservation preference or need will almost always be possible, and it behooves us to be able to justify any selections we make.

\section{What species should we concentrate on?}

Turning more deliberately to Lepidoptera, we can presume that most, probably all, of the species advanced will themselves need conservation or be useful in promoting conservation of key habitats. The collective premises are likely to include at least some of (i) the species being scarce or localised; (ii) threatened in some tangible way, with the most likely threat being loss or despoliation of limited habitat, but with definition of the threat becoming the basis for alleviative conservation management; (iii) local endemics, perhaps known only from single sites of other very narrow range; (iv) ecological specialists, perhaps with larval food plants also threatened; (v) suggested reliably to be of conservation concern and so (vi) accepted as needing support and management. Many are likely also to be listed formally on some advisory or legal schedule of 'threatened species', a step that elicits very mixed reactions from people and, however well-intentioned, can sometime impede information gathering and study of critical value for conservation (Sands \& New 2002). We are highly likely to need further basic research on such species (many of which are inherently difficult to study through being scarce and specialised) to clarify the details of management needed, and site-based management and field research demands that the site(s) be secure. Other aspects of triage may also be relevant - for example the taxonomic lineage of the species and the vulnerability and ecological features of the biotope it inhabits may influence ranking for priority. However species may be selected, ability to differentiate those species unambiguously is needed, and not always present. Two practical counters to this are available: to employ taxon groups above single species level as the units either because of conjoint needs (Maculinea butterflies, Synemon sun-moths) or an easily recognisable common appearance within which only some species are of concern (birdwing butterflies). Either approach, used with care, may enhance conservation attention. 


\section{HOW CAN WE DO IT?}

Two practical restrictions for insect species-level conservation efforts are immediately obvious. First, professional or agency support for insect conservation is, and is likely to remain, grossly inadequate for the tasks faced. Second, without augmentation of this resource base from community and volunteer interests, many of them supporting ('steering') flagship species, many butterfly conservation programmes could not proceed properly and many others would already have failed.

Experience has gradually led to a number of 'working rules' for fostering these wider interests, and progressing along the gradient from 'awareness communication - cooperation - support/participation' by local agencies and communities. Two time-scales are involved, and intergrade. The initial interests (awareness) may be a short-term reaction to media exposure, novelty or wider environmental concerns and wane once the initial flurry of activity attendant on crisis-management has passed. However, support may then be needed during a practical conservation programme extending over a decade or more of monitoring, site management and biological observations, so that interest must be sustained, often in competition with changing priorities as new cases arise, and the local community changes in composition and interests. Perhaps the most important unifying and integrating need is that the community has a firm sense of ownership and cooperative participation in the species/project, rather than being seen simply as a biddable work force whose activities are governed by ex cathedra direction from officialdom. Coupled strongly with this, all interested constituencies and groups should be involved. This wide input is essential in designing the initial conservation plan, because it is likely to lead to a harmonious continuing relationship based on trust, respect and consultation, with consideration of all viewpoints based on mutual inputs and understanding of both needs and constraints. A management team should represent all interested parties, in developing a plan, perhaps using some scheme similar to that outlined by New (2009), but modified for local circumstances, as a preliminary template for consideration.

Several commentators have remarked that 'volunteer groups' and interests for conservation are largely the province of societies that are 'middle class'
- those in which people can develop sympathy for conservation, extending beyond fulfilling their own immediate needs for food and living and with leisure time to devote to such more tangential activities. It is not realistic to expect people to willingly forego basic needs, and so not surprising that community support is difficult to enlist in regions with burgeoning human populations and marginal incomes. The scenarios in New Guinea and China in which 'butterfly ranching' has become an income-generating exercise of tangible benefit to local people, are paralleled by a few butterfly houses and similar commercial enterprises elsewhere in the region, but will remain exceptional, and in marked contrast to community inputs in leisure-rich societies such as Australia. In these contexts it is possible to categorise features that either encourage or discourage community interests, and to plan to foster those interests (Williams 1996). Encouragement features include ensuring that the community can identify with the conservation initiative, involving them from the earliest stages, developing programmes that consider their benefit, listening to community concerns, and gaining trust and ensuring that information is distributed in a timely and appropriate way. Discouraging interest results from failures to recognise community interests and level of ecological understanding, so that resentment may occur through apparent 'talking down' and enthusiasm dampened, failing to provide appropriate support after initiating programmes, and not facilitating any sense of ownership. In principle, but not always in practice, these pointers are transferable. Although Williams' (1996) parameters were derived initially from her experiences with vertebrate and ecosystem recovery programmes, they encapsulate well the needs for butterflies or any other flagship species.

Collectively, they emphasise the need for education and increasing awareness, and it is perhaps in this arena that greatest progress in many societies can be made. Promotion of Lepidoptera for ecotourism (including butterfly reserves), photography, educational tools in schools, for example, has been undertaken in this region. The declaration of several birdwings as 'National Butterflies' of Papua New Guinea in 1968 drew wide attention to their plight and significance. The butterfly garden at Changi International Airport (Singapore) is a notable feature. Appearance of Lepidoptera on stamps attracts wide attention from philatelists and tourists. 
Examples could be multiplied substantially, but the collective image of butterflies and, more rarely, other Lepidoptera, is associated strongly with conservation need by such activities. Icon species, with individual interest or special significance and that people wish to see (perhaps as ecotourists) or conserve, are a fundamental component of bridging the concepts of diversity and individual species vulnerability, but this is a context far different from needs for enhancing practical conservation management of those species.

Cooperation needs planning and continued review. It can not proceed from neglect, arrogance, presumption and lack of tact in dealings amongst participants. Any of these may be perceived as 'issuing orders'. Insisting on accountability or deadlines, however routine to managers, is often inimical to volunteer inputs. Tensions amongst varied groups of people with differing priorities can arise from many sources, not least the individual personalities involved. 'Chains-of-command' across government agencies and scientific bodies (as, commonly, the drivers of the programmes) need considerable tact. The collective views of constituents or stakeholders with different interests can create conflict without clear discussion. Ineffective communication - perhaps by use of technical terms when they are not strictly needed, or lack of explanation of the measures and procedures and why they are to be used or proposed for consideration must also be avoided. Notwithstanding this, effective leadership and coordination of the management team is necessary, together with responsible documentation of the management scheme and its progress (objectives, practical steps, timing, budget, lead participants and control, and any other component of the programme) adopted.

Supportive "Friends' groups" for any species or site may arise independently of any more official body, particularly in communities with a strong environmental ethic or in which naturalists' clubs or similar interests occur. Any such important initiatives merit the strongest encouragement, not least as relevant and knowledgeable local advocates, and the most basic and informed support likely to be available and, in some cases, leading to effective networks of people for conservation support. The Australian case for the Bathurst copper butterfly (Paralucia spinifera) is an excellent example (Nally 2003). In this example, the initiative by a local café in Lithgow designating themselves as a sponsor helped to generate interest and support within the local community and led to participation by local groups in measures such as growing and planting larval food plants, education (including preparation of instruction kits), weed control on butterfly sites, and others. 'Local pride', involving the vital sense of ownership, may come from simplesounding measures, one of which is implied above the allocation of a local patronymic common name. $P$. spinifera is known as the Bathurst copper or Lithgow copper, after the two major towns within its narrow range in New South Wales, as well as by 'purple copper' as a more neutral epithet. Dedication of a site as a reserve named for a local supporter or dignatory is also likely to appeal. One of the dedicated reserves for the Eltham copper (Paralucia pyrodiscus lucida, a close relative of $P$. spinifera and named for an outer eastern suburb of Melbourne, Victoria) is called the 'Pauline Toner Reserve' commemorating the late local State parliamentarian whose enthusiasm and support were important catalysts in the initial conservation campaign.

Adoption of species as local icons, supported by publicity such as information leaflets, education initiatives, involvement of local people and cooperation with managers of sites, perhaps coordinated by meetings or informal on-site gatherings (where the sites can withstand this pressure), all contribute to local pride. The common flow-on is realisation that the taxon is of much more than local importance, so that far wider advocacy can also be very worthwhile. Local and national entomological societies may provide sources of information and energy - in Australia, the Entomological Society of Queensland and the Entomological Society of Victoria have both helped to guide butterfly conservation projects, and the national science agency (CSIRO) was a critical driver of much of the campaign for the Richmond birdwing butterfly (Ornithoptera richmondia) (Appendix 1, Sands et al. 1997).

Endemism itself generates conservation value amongst threatened species, so that a defined geographical transition from local to national global significance (such as by inclusion on a national Red Data Book or entry on the global IUCN Red List) may help emphasise value to local managers. Much of the impetus for conservation of birdwing butterflies, for example, has historically come from people who have 
never seen them in the wild, nor visited the countries in which they occur: the conservation interest has arisen from the spectacular aesthetic appeal of birdwings, and their flagship values as ambassadors for tropical forest ecosystems.

\section{WHAT MIGHT WE EXPECT TO GAIN?}

Restricted resources available for insect conservation ensure that, in many instances, conservation programmes simply cannot be undertaken properly from these alone, and depend critically on additional inputs and interest from the wider community. With willing participation of volunteer helpers, every aspect of planning and management may become better focused and more easily achieved, not least by incorporating expertise, experiences, interest and labour not available from any other source, or expensive and difficult to procure. For Lepidoptera, examples of this aid include (i) undertaking additional surveys to detect the species; (ii) monitoring of known populations; (iii) undertaking research tasks under guidance; (iv) other tangible physical help in site maintenance - activities such as fencing, weed control, pruning, sanitation, preparation of signage, and many others; (v) advocacy and support, perhaps through education programmes or informal talks; (vi) fund-raising activities. Any such list is bounded only by definition of needs in any individual case. In conjunction, some informal record of interest expressed and available as special needs occur may help to respond to suggestions or queries that arise. Few reactions are more off-putting to people asking how they can help, than to be met with only a vague and non-welcoming response. A simple leaflet about the insect and its needs can make substantial positive impression.

It is, however, important that coordination of the whole project is maintained, and that impetuous and unplanned activities are not pursued. The management team, in reviewing and setting priorities amongst all objectives and tasks needed, will consider all viewpoints and activities proposed within the overall mission of the project and in the spirit of the flexible (adaptive) management. That approach can incorporate unexpected changes as they arise, without compromising the integrity of the programme. Concerned 'citizen scientists' occur in all walks of life, and many people interested in natural history are passionate about participating or helping in conservation activities once they become aware of the need. More focused enterprises have led to such interest groups being incorporated into surveys, such as for alien ladybird beetles in North America (Losey et al. 2007, through Cornell University), but the roles of volunteer observers have long been implicit in surveys and documentation of Lepidoptera, such as for the Monarch Butterfly Danaus plexippus in North America (one of few globally-acknowledged flagship insect species, and the focus of continuing conservation need, linked to its spectacular seasonal migrations: Brower 1995) and the preparation of the Atlas of British butterflies (Asher et al. 2001). Whilst any related activities are likely to contribute to a conservation programme, it is commonly important to adhere to some pre-agreed sequence of priorities to gain most planned benefits.

\section{HABITAT AS A CENTRAL ISSUE}

A moth or butterfly can thrive only in places where its critical resources can be assured at times they are needed; a 'habitat' is much more than just 'a place to live', and calls for habitat protection, augmentation and restoration are the most universal themes in species management plans. They reflect that habitat loss or change is the greatest, and potentially universal, threat to the species (New et al. 1995). Most commonly, Lepidoptera management is site-focused rather than primarily resource-focused. But, in many cases, it is not really known which characteristics of the site render it suitable for the particular species, and how those characteristics may be managed. Even for the well-known British butterflies, as Dennis has recently emphasised (Dennis 2010), many important aspects of their resource needs and usage are still unclear.

Following the interpretation advanced by Dennis and his colleagues in that context (Dennis et al. 2006, 2007), 'resources' fall into two broad categories. 'Consumables' are larval foodplants, adult nectar sources and (for some Lycaenidae) obligate mutualistic ants - the more obvious needs that are the most regular focus of conservation enhancement, both in terms of supply and distribution. 'Utilities' are the numerous wider environmental factors needed, such as - perhaps bare ground for basking, flyways for patrolling, perches for territorial behaviour, retreats for overwintering or for pupation, particular microclimates and topography, 
or any other of the numerous factors that govern an insect's normal behaviour and development, and allow it access to consumables. Ultimately, understanding resource needs and supply and assuring their availability is the core of species management. Many of the practical tasks that can devolve on community support relate directly to this, and the examples below illustrate this focus, with considerations of resource quantity, quality, accessibility, distribution and security encompassing most aspects of 'habitat' suitability. Management may need to be concentrated on sites currently occupied by the flagship species, or to explore the needs for translocation of insects, sometimes accompanied by preparation of additional sites to receive them. Without understanding resource needs, it may be difficult to render any site management optimal.

Representative problems and attendant tasks include:

1. Dealing with problems on small isolated sites as remnants in a formerly hospitable landscape now changed and unsuitable, with the presumption that the insect population is functionally isolated.

2. Ensuring adequate continuing supply of consumables in a dynamic environment, such as by countering successional changes. Most commonly this may entail enhancement of foodplants, perhaps from nursery-grown stock, to sustain carrying capacity and distribution and to facilitate connectivity.

3. Linked strongly with this, prevention of additional threats: removal of alien weeds or other invasives, general sanitation, prevention of vandalism, assuring site security - perhaps by changes in tenure and ownership.

4. Considering range-wide or landscape-level conservation for the species and how the species' needs may be integrated more widely, and orchestrated with other conservation priorities in the area or for the particular biotope involved.

\section{SOME EXAMPLES FROM AUSTRALIA: PROCESS AND BENEFITS}

The above entails assuring site security, definition and removal of further threats, defining conservation objectives and the measures to achieve these, and planning logical ways to undertake these, with formulation of budget and allocation of primary responsibility. This ideal is rarely possible, and even many of the most important Lepidoptera species conservation programmes have simply 'grown' and developed gradually as their complexities become evident. Realistic retrospective appraisal of how and why particular projects have succeeded or failed can be instructive.

Some of the above points on roles of flagship Lepidoptera in wider habitat conservation, and interacting with local communities to achieve this, are demonstrated by outlines of three recent and continuing projects in Australia. The social and environmental pressures influencing how each of these has arisen and progressed help to emphasise that scientifically-based conservation management proceeds in much wider governing environment in which community interest and support is critical. The cases differ in emphasis, but are unified by the taxa being signalled formally as threatened, and some comparative details are summarised in Appendix 1. They help to demonstrate the practical uses of flagships in a variety of different ecological and conservation contexts. The first two are the longest-running such campaigns for insects in Australia.

1. The Eltham Copper Butterfly (Paralucia pyrodiscus lucida Crosby, Lycaenidae) exemplifies taxa on small urban remnant sites, in enforcedly isolated populations, presumed survivors from a former much wider range, and for which conservation is essentially site-based and necessarily intensive. It is a flagship for urban remnant sites close to Melbourne.

2. The Richmond Birdwing Butterfly (Ornithoptera richmondia (Gray), Papilionidae) exemplifies taxa with high aesthetic appeal and that can range widely over a landscape whilst dependent on particular resources within complex subtropical forest environments. It is a flagship for subtropical forests, and for the dangers of introduced species.

3. The Golden Sun-moth (Synemon plana Walker, Castniidae) represents an endemic genus, and is restricted to native grassland areas in the south east, where it is listed nationally as critically endangered. It is a flagship for native grasslands, which are regarded as the most threatened ecosystem in the region and have been reduced to no more than $1 \%$ of their former extent by urban and agricultural developments. $S$. plana is one of a trio of flagship animal species viewed as critical advocates for threatened native grasslands the three are publicised as 'a legless lizard, an earless 
dragon, and a mouthless moth' but the moth is accorded at least the same significance as the two reptiles; in itself this scenario is unusual.

\section{WHAT NEXT?}

The three Australian cases noted above and in Appendix 1 are progressing within a social environment in which sympathy for butterflies is wellestablished and 'respectable', and in which community support is likely to be accessible. This is not always the case, unless very tangible, material, benefits can be demonstrated. Even then, fostering sympathy for even the most notable of insects amongst vast human populations striving for basic necessities and with incomes measured in, at most, a few dollars a day, will remain difficult or impossible. Many aspects of the public relations exercises that are almost standard components of conservation campaigns for charismatic insects in Australia or North America are almost impossible; people simply cannot 'buy the T-shirt'.

The most wide-ranging attempt to use a butterfly flagship in this way has been for Queen Alexandra's Birdwing (Ornithoptera alexandrae) in Papua New Guinea, based on it being a powerful and popular symbol, accepted globally as significant, for tropical rainforest as amongst the richest of all terrestrial biotopes. Always elusive, the butterfly has been under threat from two forms of forest loss - replacement of primary forest by commercial oil palm plantations, and timber extraction. The broad conservation plan during the1990s, in large part funded from Australia's programme of foreign aid, sought to promote $O$. alexandrae as a flagship/umbrella species to reduce primary dependence on rain forest and reduce the need to clear it, whilst facilitating income generation and alternative livelihoods for local people. Some aspects of the programme were discussed by New (2007), and the main point recapitulated here is the attempt to promote a notable flagship species into all of the interacting environmental, social and economic milieu throughout its full geographical distributional range. Operations on this large scale are unlikely to become numerous, not least because of their duration and need for resources over a long period. They are also difficult to promote without direct and readily forthcoming incentives for local communities or landholders to participate, because the most immediate perception is often that the conservation activities will restrict activity and lead to loss of income.

However, increasing calls for single-species focus in insect conservation to be supplanted by wider approaches to conserve habitats within landscapes, or assemblages - however wise in anticipating greater returns for effort and limited resources, and considered widely to be the only viable path to sustainability - in many cases fail to appeal in the same way as conserving individual species. They are also more complex to monitor or otherwise evaluate, particularly for the multitudes of small or less-conspicuous organisms. Lepidoptera assemblages are indeed valuable tools in assessing ecosystem integrity and influences of human disturbance, but many subtleties appear only on analysis at the species or near-species level. A major value of flagship species is that they constitute 'footholds' for monitoring, advocacy, and broadening community participation and interest in conservation. Individual treatments of carefully selected flagship species remind us of the intricacies of insect resource need.

If those studies are wholly replaced by broader programmes, withouttracking the fates of representative individual taxa within assemblages, we might become vulnerable to not only losing massive proportions of locally endemic species that share our world, but also to not knowing if and why this has occurred. Surely our heritage is worth more than this?

I would urge that we continue to benefit from the understanding of individual species programmes, as ambassadors for the wider importance of insects, and to strenuously encourage any ways in which community networks can be formed and fostered to assure a secure future for those species and the environments on which they, and we, depend. The reality of this interdependence is here conveyed through members of a diverse insect group that: (i) depends fundamentally on food plants for larvae; (ii) often manifest very specific associations and interdependence (iii) which are sometimes complicated further by obligate involvement with other organisms (such as mutualistic ants); (iv) contains many localised and declining species, and combined with (v) public acceptance and sympathy for their wellbeing together with (vi) an increasing variety of demonstrated conservation successes. Many of these cases have involved highly innovative management steps based on sound and increasing biological understanding and 
common sense, and the outcomes indeed render many Lepidoptera worthy 'ambassadors for biodiversity'. Priority tasks for the future include refining and extending this influence further, and seeking means to increase the conservation benefit and influence of these studies. As one example, the central importance of resource/habitat protection is still based on very inadequate knowledge of distribution patterns and local richness of Lepidoptera within areas already set aside for conservation. In such areas both study and necessary management could be undertaken without the complex problems that arise from work on private lands or those of uncertain tenure; for Australia, systematic surveys of selected insect groups in major protected areas have been advocated (Sands \& New 2003). Their advantages include basic inventory and information gathering, aiding credibility of conservation advocacy and status allocation. That template helps in setting priorities amongst the many deserving species that are potentially flagships, and honing their use in wider conservation programmes for the critical habitats on which they and numerous other species depend. Without fostering such species as powerful messengers, much of the need for conservation would be much more difficult to convey effectively.

Flagship Lepidoptera are amongst the most potent tools for promoting awareness of insect conservation need, and in increasing community awareness through scales extending from local to national, or even wider. Key organisations, such as Butterfly Conservation (UK, now expanded to Europe) and the Xerces Society (US) had their gestation in this way, with their foundations from promotion of flagship butterflies now extended to much wider influence and support.

\section{REFERENCES}

Andelman, S.J. \& W.F. Fagan (2000). Umbrellas and flagships: efficient conservation surrogates or expensive mistakes? Proceedings of the National Academy of Sciences 97: 5954-5959.

Asher, J., M. Warren, R. Fox, P. Harding, G. Jeffcoate \& J. Jeffcoate (2001). The Millennium Atlas of Butterflies in Britain and Ireland. Oxford University Press, Oxford, $\mathrm{xx}+433 \mathrm{pp}$.

Bonebrake, T.C., L.C. Ponisio, C.L. Boggs \& P.R. Ehrlich (2010). More than just indicators: a review of tropical butterfly ecology and conservation. Biological Conservation
143: $1831-1841$.

Bowen-Jones, E. \& A. Entwistle (2002). Identifying appropriate flagship species: the importance of culture and local contexts. Oryx 36: 189-195.

Brower, L.P. (1995). Understanding and misunderstanding the migration of the Monarch Butterfly (Nymphalidae) in North America. Journal of the Lepidopterists' Society 49: 304-385.

Dennis, R.L.H. (2010). A Resource-based Habitat View for Conservation - Butterflies in the British landscape. WileyBlackwell Publishing, Oxford, xii+406pp.

Dennis, R.L.H., T.G. Shreeve \& H. Van Dyck (2006). Habitats and resources: the need for a resource-based definition to conserve butterflies. Biodiversity and Conservation 15: 1943-1968.

Dennis, R.L.H., T.G. Shreeve \& D.A. Sheppard (2007). Species conservation and landscape management: a habitat perspective. pp. 92-126. In: Stewart, A.J.A., T.R. New \& O.T. Lewis. (eds). Insect Conservation Biology. CAB International, Wallingford.

Fleishman, E. \& D.D. Murphy (2009). A realistic assessment of the indicator potential of butterflies and other charismatic taxonomic groups. Conservation Biology 23: 1109-1116.

Franklin, J.F. (1993). Preserving biodiversity: species, ecosystems, or landscapes? Ecological Applications 3: 202-205.

Hettinger, N. (2010). Animal beauty, ethics and environmental preservation. Environmental Ethics 32: 115-134.

[Hong Kong (2007)]. Hong Kong Declaration on the Conservation of Lepidoptera. pp. 148-149. In: Kendrick, R.C. (ed.) Proceedings of the First South East Asian Lepidoptera Conservation Symposium, Kadoorie Farm and Botanic Garden, Hong Kong.

IUCN (2010). The IUCN Red List of Threatened Species (www.iucn redlist.org/)

Kendrick, R.C. (2007). The conservation assessment of moths in Hong Kong. pp. 71-82. In: Kendrick, R.C. (ed.). Proceedings of the First South East Asian Lepidoptera Conservation Symposium, Kadoorie Farm and Botanic Garden, Hong Kong.

Kitching, R.L. (2007). Tigers, lobsters, hawks and pugs: moth assemblages in conservation [abstract and presentation notes]. pp. 9-15. In: Kendrick, R.C. (ed.) Proceedings of the First South East Asian Lepidoptera Conservation Symposium, Kadoorie Farm and Botanic Garden, Hong Kong.

Kristensen, N.P., M. Scoble \& O. Karscholt (2007). Lepidoptera phylogeny and systematics: the state of inventorying moth and butterfly diversity. Zootaxa 1668 : 699-747.

Losey, J.E., J.E. Perlman \& R. Hoebeke (2007). Citizen scientist rediscovers rare nine-spotted ladybird, Coccinella novempunctata, in eastern North America. Journal of Insect Conservation 11: 415-417.

Nally, S.C. (2003). Community involvement in the conservation of endangered purple copper butterfly Paralucia spinifera 
Edwards and Common (Lepidoptera: Lycaenidae). Records of the South Australian Museum, Monograph series 7: 217-224.

New, T.R. (1997). Are Lepidoptera an effective 'umbrella group' for biodiversity conservation? Journal of Insect Conservation 1: 5-12.

New, T.R. (2000). How to conserve the 'meek inheritors'. Journal of Insect Conservation 4: 151-152.

New, T.R. (2007). Broadening benefits to insects from wider conservation agendas. pp. 301-321. In: Stewart, A.J.A., T.R. New \& O.T. Lewis (eds). Insect Conservation Biology. CAB International, Wallingford.

New, T.R. (2009). Insect Species Conservation. Cambridge University Press, Cambridge, xiv+256pp.

New, T.R. (2010). Butterfly conservation in Australia: the importance of community participation. Journal of Insect Conservation 14: 305-311.

New, T.R., R.M. Pyle, J.A. Thomas, C.D. Thomas \& P.C. Hammond (1995). Butterfly conservation management. Annual Review of Entomology 40: 57-83.

Robinson, G.S., K.R. Tuck \& M. Shaffer (1994). A Field Guide to the Smaller Moths of South-East Asia. The Natural History Museum, London, 309pp.

Sands, D.P.A. \& T.R. New (2002). The Action Plan for Australian Butterflies. Environment Australia, Canberra, vi $+377 \mathrm{pp}$.

Sands, D.P.A. \& T.R. New (2003). Coordinated invertebrate surveys in Australia's national parks: an important tool in refining invertebrate conservation management. Records of the South Australian Museum, Monograph series 7: 203208.

Sands, D.P.A., S.E. Scott \& R. Moffatt (1997). The threatened Richmond birdwing butterfly (Ornithoptera richmondia [Gray]): a community conservation project. Memoirs of Museum Victoria 56: 449-453.

Simaika, J.P. \& M.J.Samways (2010). Biophilia as a universal ethic for conserving biodiversity. Conservation Biology 24: 903-906.

Simberloff, D. (1998). Flagships, umbrellas and keystones: is single-species management passé in the landscape era? Biological Conservation 83: 247-257.

Williams, S. (1996). Community involvement in the species recovery process: insights into successful partnerships. pp. 87-96. In: Stephens, S. \& S. Maxwell (eds). Back from The Brink. Refining The Threatened Species Recovery Process. Surrey Beatty \& Sons, Chipping Norton.

Wilson, E.O. (1987). The little things that run the world (the importance and conservation of invertebrates). Conservation Biology 1: 344-346.

Yen, A.L., T.R. New, B. Van Praagh \& P.J. Vaughan (1990). Invertebrate conservation: three case studies in southeastern Australia. pp. 207-224. In: Clark, T. \& J.H. Seebeck (eds). Management and Conservation of Small Populations. Chicago Zoological Society, Brookfield, Illinois.

Appendix 1. Outline summaries of three conservation programmes involving flagship taxa of Lepidoptera in eastern Australia

\section{Paralucia pyrodiscus lucida Crosby (Lycaenidae, the Eltham Copper Butterfly, near Melbourne populations).}

Subspecies described from outer eastern Melbourne, reduced heavily by urban expansion, but small populations confirmed in 1987 on small (1-2 hectares) isolated sites, some scheduled for imminent housing development. Initial interest coincided with development of Victoria's Flora and Fauna Guarantee Act 1988; Minister for Conservation approved development moratorium pending status investigation, as the first insect used as a flagship in the State. Local community highly sympathetic and adopted the copper as a symbol for conservation, with a continuing 'Friends' group'; major funding from government (commonwealth and state) and local efforts enabled purchase and reclassification of severa sites, with three declared as dedicated butterfly reserves bearing a strong sense of local 'ownership'.

Ecology: Larvae are monophagous on Bursaria spinosa (Pittosporaceae) and have mutualistic relationship with Notoncus ants; they are nocturnal and pass the day in ant nests at the base of foodplants and ants 'shepherd' them up plants to feed at night. Small area of sites limits population size, and Eltham populations have butterflies present throughout summer. Populations are site-dependent, isolated by housing development and paved roads.

Conservation scenario: Small isolated urban sites, on which butterfly populations are conservation-dependent and management needs can be intensive and individualistic. Threats include natural succession leading to canopy closure and loss of Bursaria, weed invasion and other 'edge effects', vandalism and waste dumping, and fuel buildup leading to perceived dangers from fires by local residents. Sites span a variety of administrative tenures, and on each, butterflies, Bursaria and ants are all distributed patchily.

Conservation measures: Butterfly listed for protection, and distribution and abundance trends in main sites evaluated annually by counts of adults and caterpillars by volunteer community helpers. Management emphasis on sustaining site quality and resource supply, whilst avoiding excessive human intrusion into small sites. Main sites with permanently marked $10 x$ $10 \mathrm{~m}$ grids, in which individual occupied foodplants tagged for cumulative recording. Practical steps include weed removal (hand labour) and suppression / successional regeneration / canopy opening- fuel reduction by hot control burning; general high intensity continuing management with substantial community input, including representation on statewide management group.

Selected references: Braby et al. (1999), New et al. (2000), Webster (2008), New (2010)

2. Ornithoptera richmondia (Gray) (Papilionidae, the Richmond Birdwing, south eastern Queensland and north eastern New South Wales).

The most southerly Australian birdwing, found in rainforest habitats that have been largely cleared to leave fragmented pockets and cause loss of the birdwing over much of its former range. Species with high public appeal, so declines accepted as realistic and undesirable; initially listed as of conservation significance in 1974, and a focus of major community conservation programme since the late 1980s; this has emphasised habitat features on range-wide or landscape level.

Ecology: Larvae feed on two species of native vines (Aristolochiaceae) found in rainforest, the main one being Pararistolochia praevenosa, reduced in parallel with forest loss and, with the butterfly, now mainly found in riparian forest remnants. The butterfly is a strong flyer and can track vines over substantial distances, so conservation has landscape focus.

Conservation scenario: In addition to the major losses of primary habitat, the species' decline is exacerbated by spread of an alien ornamental species of vine, Dutchman's Pipe (Aristolochia elegans) into remaining forests and elsewhere across the landscape. This vine is highly attractive to female $O$. richmondia for oviposition, but foliage is toxic to hatchling caterpillars, which die after feeding. The major conservation needs are thereby twofold; enhancement of native foodplants by extensive plantings, and removal of the alien vine throughout the butterfly's range.

Conservation measures: Major community involvement from outset of project, with major emphasis on production of nursery-grown native vines for distribution to schools and individuals for augmentation planting and observation of butterfly colonisation, removal of Dutchman's pipe and 
protection of sites occupied by the birdwing. Range-wide coordination through conservation agencies, with early involvement of CSIRO's Double Helix Club encouraging interests of young people: by 1997 more than 300 schools were involved and more than 29,000 nursery-propagated vines had been distributed. Later development of the Richmond Birdwing Recovery Network Inc. (now Richmond Birdwing Conservation Network), with more than 400 members in mid-2009, with major emphasis on growing and planting vines on public and private land, in a system of 'corridors' to expand the birdwing's range by facilitating its natural movement. A lively and informative network newsletter is augmented by meetings involving instruction sessions on vine identification and propagation (with handbook manuals produced), visiting lecturers and field trips to maintain coordination of activities. Captive breeding of Richmond birdwing has been attempted in large field cages.

Selected references: Sands et al. (1997), Sands \& Scott (2002), Sands (2008).

\section{Synemon plana Walker (Castniidae, the Golden Sun-moth, south} eastern mainland Australia).

One of an endemic radiation of about 40 Castniidae, many of them threatened (some perhaps extinct), due to loss of native grasslands. $S$. plana is listed federally as 'critically endangered' and also listed individually under each of the three range Acts (for Victoria, New South Wales, Australian Capital Territory), reflecting the extensive losses of native lowland grasslands for agriculture, urban and industrial developments throughout the region: many remaining fragments are close to cities and under continued pressure for development. As a symbol for one of the most threatened regional ecosystems, S. plana is one of few high profile moths in Australia. It occurs mostly on small isolated grassland fragments in varying stages of degradation, and most populations appear to be small difficulties of detecting and enumerating moths have involved considerable volunteer help and interest from community environmental groups.

Ecology: S. plana is difficult to study. Caterpillars are subterranean and feed on roots of native grasses; it is not yet clear whether the lifecycle takes one, two, or even three years. Adults are shortlived (about three to five days) and, with rudimentary mouthparts, do not feed. Males fly fast, but only under warm, calm, dry conditions and for a few hours in the middle of the day: survey opportunities are thereby limited. Females fly little, but mostly rest on the ground, responding to overflying males by exposing their bright orange hind wings. At any site, the flight season extends over about six to eight weeks, but rapid turnover of individuals renders counting moths difficult, as numerous visits are needed. Apparent distribution on a site may change over this time, as emergence may be influenced by soil temperatures and, thus, microtopography.

Conservation scenario: Detection and protection of occupied sites dominates conservation concerns; many of these are small, isolated close to settlement, and threatened by imminent development; many are also highly degraded by weed invasion and alien grasses introduced for stock grazing. With improved knowledge of moth detection, S. plana is being found progressively at many such sites.
Conservation measures: Advocacy for S. plana, with two threatened grassland lizards also dependent on remnant native grasslands, has led to a 'portfolio' approach with these three flagship species. Major input from volunteers, including field days organised through community environmental groups, in detecting presence of moths in grassland sites, and attempting to assess distributions of populations. Primary conservation need is to prevent sites being lost to development, and to assess whether realistic compromise, such as use of 'habitat offsets' may be viable in helping to maintain habitat. One of two foci (with S. selene) of first dedicated sun-moth reserve; only one of eight species of Synemon in Victoria may be 'secure' without such measures.

Selected references: Douglas (1993, 2004), Gibson \& New (2007).

\section{REFERENCES}

Braby, M.F., B.D. Van Praagh \& T.R. New (1999). The dull copper, Paralucia pyrodiscus (Lycaenidae). pp. 247-260. In: Kitching, R.L, E. Scheermeyer, R.E. Jones \& N.E. Pierce (eds). Biology of Australian Butterflies. CSIRO Publishing, Collingwood.

Douglas, F. (1993). The conservation status, distribution and habitat requirements of diurnal Lepidoptera in central and western Victoria (Part 1: Family Castniidae). Department of Natural Resources and Environment, East Melbourne, 29pp.

Douglas, F. (2004). A dedicated reserve for conservation of two species of Synemon (Lepidoptera: Castniidae) in Australia. Journal of Insect Conservation 8: 221-228.

Gibson, L. \& T.R. New (2007). Problems in studying populations of the golden sun-moth, Synemon plana (Lepidoptera: Castniidae) in south eastern Australia. Journal of Insect Conservation 11: 309-313.

New, T.R. (2010). Butterfly Conservation in south-eastern Australia; Progress and Prospects. Springer, Dordrecht, $\mathrm{x}+190 \mathrm{pp}$.

New, T.R., B.D. Van Praagh \& A.L.Yen (2000). Fire and the management of habitat quality in an Australian lycaenid butterfly, Paralucia pyrodiscus lucida, the Eltham copper. Metamorphosis 11: 154-163.

Sands, D. (2008). Conserving the Richmond Birdwing Butterfly over two decades: where to next? Ecological Management and Restoration 9: 4-16.

Sands, D.P.A. \& S. Scott (2002). The Richmond birdwing butterfly (Ornithoptera richmondia [Gray]): its natural history and progress towards recovery. pp. 32-47. In: Sands, D. \& S. Scott (eds). Conservation of birdwing butterflies. SciComEd Pty \& THECA, Chapel Hill, Brisbane, 48pp.

Sands, D.P.A., S.E. Scott \& R. Moffat (1997). The threatened Richmond Birdwing Butterfly (Ornithoptera richmondia [Gray]): a community conservation project. Memoirs of Museum Victoria 56: 449-453.

Webster, A. (2008). Eltham Copper Butterfly Paralucia pyrodiscus lucida. Draft Flora and Fauna Guarantee Action Statement (revision, Action Statement no 39). Department of Sustainability and Environment, Victoria. 